\title{
Air pollution and mortality in Barcelona
}

\author{
Jordi Sunyer, Jordi Castellsagué, Marc Sáez, Aurelio Tobias, Josep M Antó
}

\begin{abstract}
Study objectives - Studies conducted in Barcelona reported a short term relation between daily air pollutant values and emergency department admissions for exacerbation of chronic obstructive pulmonary diseases and asthma. Air pollution in Barcelona is mainly generated by vehicle exhaust and is below the World Health Organization air quality guidelines. The acute relation between air pollution and mortality was assessed.

Design - Daily variations in total mortality, mortality in subjects older than $\mathbf{7 0}$ years, and cardiovascular and respiratory mortality were related with daily variations in air pollutants for the period 198591, using autoregressive Poisson regression models that allow to control for temperature, relative humidity and variables handling temporal and autoregressive patterns.
\end{abstract}

Main results - Black smoke and sulphur dioxide $\left(\mathrm{SO}_{2}\right)$ were related to total mortality (relative risks (RR) for $100 \mu \mathrm{g} / \mathrm{m}^{3}=$ 1.07 and 1.13 respectively), elderly mortality $(R R=1.06$ and $1 \cdot 13)$, cardiovascular mortality $(R R=1 \cdot 09$ and $1 \cdot 14)$, and respiratory mortality $(R R=1 \cdot 10$ and $1 \cdot 13)$; all the associations being statistically significant, except for respiratory mortality $(p=0 \cdot 07)$. The association between $\mathrm{SO}_{2}$ and respiratory mortality was stronger in summer $(1.24, p<0.01)$ than in winter $(1 \cdot 08, p>0 \cdot 1)$. Oxidant pollutants (nitrogen dioxide and ozone) were positively related with elderly mortality $(R R=1.05$ and 1.09 , respectively) and cardiovascular mortality $(R R=1.07$ and 1.09$)$ during the summer $(p<0.05)$, but not during the winter.

Conclusions - Current air pollutant levels were related to mortality in Barcelona. These results were consistent with similar studies in other cities and coherent with previous studies with emergency room admissions in Barcelona.

( $f$ Epidemiol Comm Health 1996;50(Suppl 1):S76-S80)

Department of

Epidemiology and

Public Health, IMIM,

Universitat Autonoma

de Barcelona,

Dr Aiguader 80,

08003 Barcelona,

Spain

J Sunyer

J Castellsagué

M Sáez

A Tobias

J M Antó

Correspondence to: Dr J Sunyer.
Barcelona offers a useful environmental scenario in which to study air pollution health effects. Barcelona is mainly polluted by vehicle exhausts and the climate is mild. Levels of black smoke (BS), particles, and nitrogen dioxide $\left(\mathrm{NO}_{2}\right)$ are in the highest range for western cities participating in the APHEA project, ${ }^{1}$ although they are within the World Health Organization air quality guidelines. ${ }^{2} \mathrm{~A}$ recent chemical analysis of particles in the air in Barcelona showed that vehicle exhausts accounts for $35 \%$ of the total particulate amount whereas industry and heat emissions contribute only $1 \%{ }^{3}$ Some $50 \%$ of the particles were attributed to soil dust. ${ }^{3}$ Correlation between temperature and pollutants is relatively low, particularly in summer, ${ }^{4}$ facilitating the adjustment for temperature.

Studies conducted in Barcelona reported a short term relation between air pollution levels and the number of emergency department admissions for exacerbation of chronic obstructive pulmonary diseases ${ }^{4-5}$ and asthma. ${ }^{6}$ Sulphur dioxide $\left(\mathrm{SO}_{2}\right)$ and $\mathrm{BS}$ were the pollutants related to chronic obstructive pulmonary disease, ${ }^{5}$ and although it is a complex correlation, an independent association for both pollutants was found. ${ }^{5} \mathrm{BS}$ and $\mathrm{NO}_{2}$ were the pollutants related to asthma. ${ }^{6}$ We studied the coherence between our previous findings on emergency department admissions and the present study on mortality, and the consistency with studies on mortality carried out in other cities representing a wide range of environments. In addition, we used the mortality data to enable us to extend the series of data used for emergencies. In particular, the objective of the present paper was to assess the relation between air pollutants and mortality, and to identify the pollutants and mortality causes involved.

\section{Methods}

The procedures followed in this study were those agreed for the APHEA protocol. ${ }^{1}$ Daily variations in mortality were related to daily variation in air pollutants using regression methods. Different markers of mortality and air pollution were assessed and are described below, as well as the variables used to control the possible confounding effect due to meteorology and temporal effects. Of particular importance is the assessment of different associations related to season, since urban atmospheres differed qualitatively by season, ${ }^{7}$ as well as the confounder variables ${ }^{56}$ and their interactions with the pollutants.

\section{HEALTH DATA}

Daily deaths for the period 1985-91 were supplied by the regional mortality register, whose completeness and quality have been proved to be good. ${ }^{8}$ Total mortality, total mortality for subjects older than 70 years, cardiovascular causes (ICD9 codes 390 to 459), and respiratory causes (ICD9 460 to 519) were assessed. 


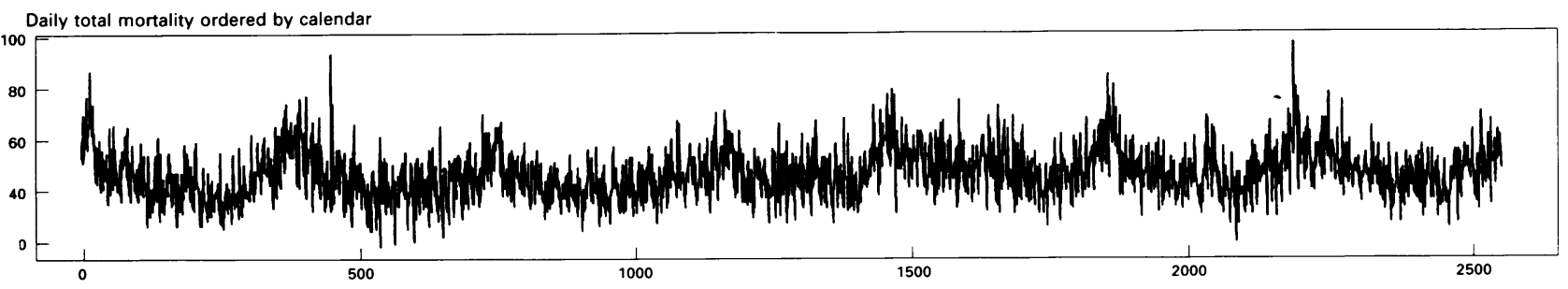

Residual $p$ values after adjustment for confounding variables
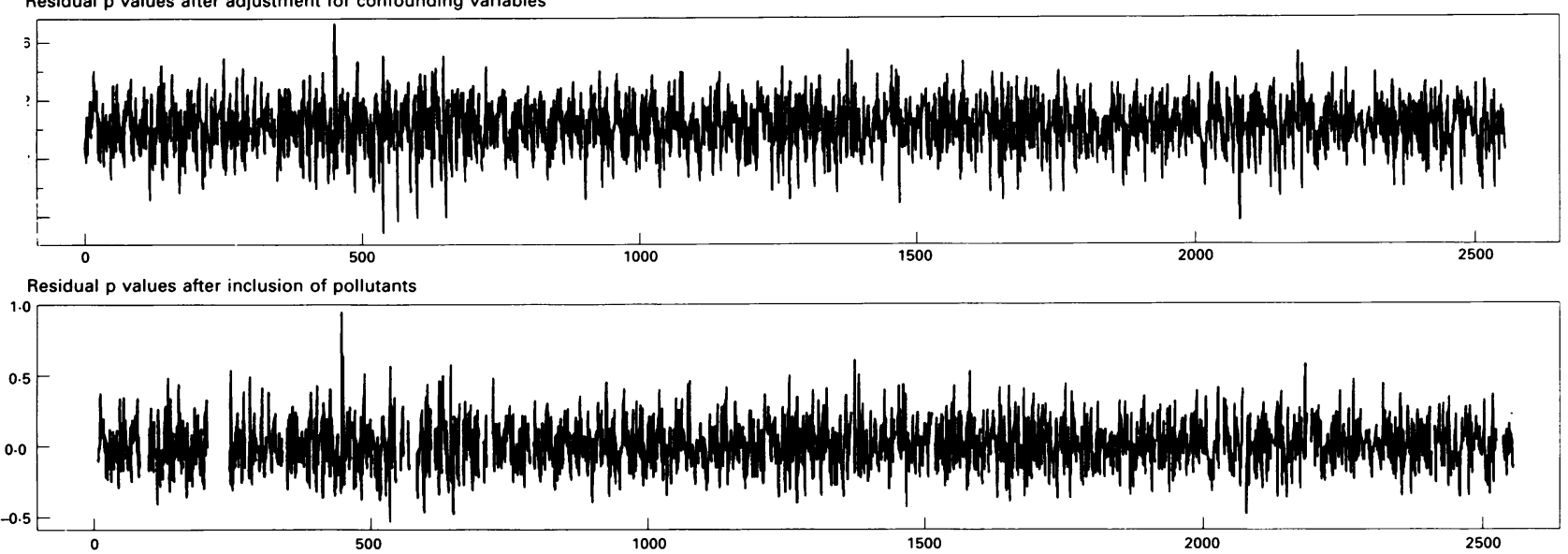

Daily total mortality (1985-1991) ordered by calendar, residual plot after adjustment for confounding variables, and final residual plot after inclusion of pollutants.

AIR POLLUTION DATA

The 24 hour average levels (collected from 8 am one day to 8 am the next day) of BS (OECD method) were computed as the arithmetic mean of the measurements provided by seven manual samplers placed around the city. In previous reports we used a larger network, but this was reduced in 1990 . Only one of the samplers gave missing values for more than $5 \%$ of days. $\mathrm{SO}_{2}$ (fluorescence method), $\mathrm{NO}_{2}$ (chemiluminescence method), and ozone $\left(\mathrm{O}_{3}\right)$ (chemiluminescence method) were averaged from three automatic stations from 1985. Data from the automatic samplers for the year 1985 were not considered because of quality problems at the beginning of the monitoring. Each station represented a different type of urban pollution (industrial, residential, and residential with high traffic). For all pollutants, missing observations for specific samplers $(19 \%$ to $25 \%$ ) were replaced by the city's average value, following the procedure stated by APHEA. ${ }^{1}$ Daily information on average temperature, relative humidity, and dew point temperature were collected by the National Meteorological Institute from a station at the airport ( $8 \mathrm{~km}$ far from the city).

\section{ANALYSIS}

The relation between pollutants and mortality was assessed using separate regression models for each pollutant and each different category of mortality. Three consecutive steps were followed according to the procedure stated by APHEA as follows:

- The parametrisation of a linear model on log transformed mortality, using least squares method to control for temporal variations, meteorology, and other confounding variables (for example, influenza epidemics) to obtain a residual plot without any temporal pattern;

- The introduction of pollutants at different lags in the previous best fitted models;

- The estimation of an autoregressive Poisson model using maximum likelihood estimations including all the variables selected in the previous steps.

In addition, interactions between pollutants and season were assessed.

A model for each log transformed mortality indicator was fitted. All models fitted included a linear and a quadratic term for trend and a dummy variable for each year to control for long term trends, a sinusoidal term up to the fourth order to control for season, a dummy variable for each day of the week and for holidays, a linear and quadratic transformation of humidity and temperature at current day values, a dummy variable for influenza epidemics, and interactions between years and sinusoidal terms to completely adjust for seasonality. Dummy variables for high humidity or very hot or cold days and interaction between these variables were included in the models but were avoided in the end since they did not improve the goodness of fit of the models. A total of 72 variables was included in the models.

Pollutants, temperature, and humidity were assessed up to a third lag, except for $\mathrm{O}_{3}$, which was assessed up to a fifth lag. Logistic and quadratic transformations of the pollutants were assessed, but for all of them the untransformed variable showed the best goodness of fit. The final Poisson regression models were fitted including up to four autoregressive parameters. Modifications of the effect in relation to season were assessed by including in the final models an interaction parameter between the air pollutant and a dummy variable for 
Table 1 Daily number of deaths and air pollutant levels (in $\mu \mathrm{g} / \mathrm{m}^{3}$ ) in Barcelona in relation to season, during the period 1985-91

\begin{tabular}{lll}
\hline Variable (no of $d$ ) & $\begin{array}{l}\text { Winter* } \\
\text { Median (range) }\end{array}$ & $\begin{array}{l}\text { Summer* } \\
\text { Median }\end{array}$ (range) \\
\hline Total mortality (2557) & $48(22-98)$ & $43(18-85)$ \\
Total mortality in those $>70$ y $(2557)$ & $33(13-68)$ & $29(11-66)$ \\
Cardiovascular mortality $(2557)$ & $21(7-47)$ & $18(5-44)$ \\
Respiratory mortality $(2557)$ & $5(1-16)$ & $4(1-15)$ \\
Temperature $(2557)$ & $11 \cdot 3(-2 \cdot 0-35 \cdot 5)$ & $19 \cdot 7(0-27 \cdot 9)$ \\
Black smoke-24 h average $(2464)_{\mathrm{O}_{2}-24 \text { h average }(1825)}^{49 \cdot 7(11 \cdot 4-66 \cdot 7)}$ & $35(10 \cdot 6-125 \cdot 6)$ \\
$\mathrm{NO}_{2}$-maximum daily value/h $(2164)$ & $46(2 \cdot 2-160)$ & $36 \cdot 4(5 \cdot 4-116 \cdot 5)$ \\
$\mathrm{O}_{3}$-maximum daily value/h $(2164)$ & $88 \cdot 4(8 \cdot 3-339 \cdot 2)$ & $97 \cdot 3(8 \cdot 0-336 \cdot 4)$ \\
\hline
\end{tabular}

* Winter $=$ October to March, and summer $=$ April to September.

Table 2 Correlation coefficients for 24 hour averages of black smoke (BS) and sulphur dioxide $\left(\mathrm{SO}_{2}\right)$ and one hour maximum value of nitrogen dioxide $\left(\mathrm{NO}_{2}\right)$ and ozone $\left(\mathrm{O}_{3}\right)$, and temperature

\begin{tabular}{lccccc}
\hline & $\mathrm{BS}$ & \multicolumn{1}{c}{$\mathrm{SO}_{2}$} & $\mathrm{NO}_{2}$ & \multicolumn{1}{c}{$\mathrm{O}_{3}$} & Temperature \\
\hline $\mathrm{BS}$ & 1 & & & & \\
$\mathrm{SO}_{2}$ & 0.634 & 1 & & & \\
$\mathrm{NO}_{2}$ & $0 \cdot 290$ & 0.262 & 1 & & \\
$\mathrm{O}_{3}$ & -0.334 & 0.181 & 0.295 & 1 & 1 \\
Temperature & -0.297 & -0.218 & -0.011 & 0.415 & 1 \\
\hline
\end{tabular}

semester (from April to September, and from October to March). The figure shows the residuals of total mortality which exemplify the process carried out with all the studied associations. Goodness of fit was assessed by visual inspection of the residual plots by an external statistician in the coordinating centre, improvement in the deviance, and the DurbinWatson test for autocorrelation. $S A S$ procedures were used for the analyses.

\section{Results}

Table 1 presents the distribution and seasonal variation of the mortality and air pollutant data. Mortality, $\mathrm{SO}_{2}$, and $\mathrm{BS}$ showed higher values in the winter period, whereas $\mathrm{O}_{3}$ showed higher values during the summer period $(\mathrm{p}<0 \cdot 05)$. Differences in $\mathrm{NO}_{2}$ in relation to season were not statistically significant. Table 2 shows the correlation between pollutants and between pollutants and temperature. $\mathrm{BS}$ and $\mathrm{SO}_{2}$ were highly correlated, whereas correlations with oxidants and between oxidants were low. $\mathrm{O}_{3}$ presented the highest correlation with temperature and $\mathrm{NO}_{2}$ the lowest; the correlation between BS and $\mathrm{SO}_{2}$ and temperature was relatively small.
Table 3 shows the relation between the different pollutants and the different mortality groups. BS and $\mathrm{SO}_{2}$ were related to total mortality in the elderly, and cardiovascular and respiratory mortality, although with the latter at the limit of the statistical significance $(p<0 \cdot 1)$. The associations with BS did not vary in relation to season whereas the association between $\mathrm{SO}_{2}$ and respiratory mortality was higher in the summer than the winter (although differences in relation to season were not statistically significant $(\mathrm{p}>0 \cdot 1))$. Similarly, $\mathrm{NO}_{2}$ and $\mathrm{O}_{3}$ were related to total, elderly, cardiovascular, and respiratory mortality, although the association with respiratory mortality was not statistically significant. The relation between oxidant pollutants and cardiovascular mortality varied by season; it was positive and significant in the summer, but negative and non-significant in the winter. For $\mathrm{BS}, \mathrm{SO}_{2}$ and $\mathrm{O}_{3}$ the association with specific mortality was stronger than with total mortality (although differences were not statistically significant, $p>0 \cdot 1)$. Most of the associations were found with current and one day lags, except for BS and $\mathrm{O}_{3}$ with respiratory mortality, which showed positive associations from the third and fifth lag day, respectively. Cumulative measures of pollutants for the three previous days did not improve the estimations with single day air pollutant values.

In order to assess whether the extensive parametrisation of the models affected the inferences and the stability of the associations obtained, we present in table 4 the changes in the coefficients of $\mathrm{BS}$ and $\mathrm{SO}_{2}$ in relation to total mortality after the consecutive inclusion of parameters in the models. The estimation of BS was found to be more sensitive to the parameters included than that for $\mathrm{SO}_{2}$. In particular, the inferences for BS would differ if the last step in the inclusion of variables was not produced.

\section{Discussion}

We found a significant association between BS and $\mathrm{SO}_{2}$ and total and specific mortality for cardiovascular and respiratory diseases. The associations between $\mathrm{SO}_{2}$ and mortality groups were stronger than those with particles, in par-

Table 3 Adjusted* relative risk and 95\% confidence intervals of mortality per each $100 \mu \mathrm{g} / \mathrm{m}^{3}$ increase in air pollutants, using Poisson autoregressive models

\begin{tabular}{|c|c|c|c|c|}
\hline Pollutant (no) & Total mortality & Mortality $\geq 70 y$ & Cardiovascular mortality & Respiratory mortality \\
\hline BS $(n=2464)$ & lag 1 & lag1 & lag1 & $\operatorname{lag} 3$ \\
\hline All the year & $1.070+(1.029,1.112)$ & $1.063+(1.016), 1.113)$ & $1.093+(1.036), 1.153)$ & $1.097(0.990,1.215)$ \\
\hline Winter & $1.069+(1.024,1.117)$ & $1.066+(1.014,1.121)$ & $1.095+(1.033,1.162)$ & $1.095(0.980,1.223)$ \\
\hline Summer & $1.063(0.989,1.144)$ & $1.049(0.963,1.144)$ & $1.078(0.973,1.194)$ & $1.096(0.889,1.351)$ \\
\hline $\mathrm{SO}_{2}(\mathrm{n}=1815)$ & lag 1 & lag 1 & lag 1 & lag 0 \\
\hline All the year & $1 \cdot 127+(1.068,1 \cdot 189)$ & $1.135+(1.065,1.209)$ & $1.145+(1.063,1.232)$ & $1.128(0.991,1.283)$ \\
\hline Winter & $1.150+(1.076,1.229)$ & $1.172+(1.083,1.267)$ & $1 \cdot 147 \dagger(1.047,1.255)$ & $1.079(0.922,1.263)$ \\
\hline Summer & $1 \cdot 100+(1 \cdot 201,1 \cdot 186)$ & $1.098+(1.007,1.198)$ & $1.139+(1.026,1.264)$ & $1.244 \dagger(1.039,1.490)$ \\
\hline $\mathrm{NO}_{2}-1 \mathrm{~h}(\mathrm{n}=2164)$ & $\operatorname{lag} 1$ & $\operatorname{lag} 1$ & $\operatorname{lag} 1$ & lag 0 \\
\hline All the year & $1.034 \dagger(1.013,1.055)$ & $1.042 \dagger(1.017,1.068)$ & $1.038 \dagger(1.009,1.068)$ & $1.026(0.966,1.089)$ \\
\hline Winter & $1.026(0.995,1.058)$ & $1.033(0.996,1.110)$ & $0.999(0.957,1.043)$ & $0.996(0.908,1.094)$ \\
\hline Summer & $1.040+(1.013,1.068)$ & $1.050+(1.018,1.083)$ & $1.069+(1.030,1.110)$ & $1.047(0.970,1.130)$ \\
\hline $\mathrm{O}_{3}-1 \mathrm{~h}(\mathrm{n}=2164)$ & lag 0 & lag 1 & lag 1 & lag 5 \\
\hline All the year & $1.048+(1.012,1.086)$ & $1.042 \dagger(1.003,1.082)$ & $1.058+(1.009,1.111)$ & $1.071(0.962,1.192)$ \\
\hline Winter & $1.026(0.965,1.091)$ & $1.002(0.940,1.068)$ & $0.992(0.911,1.079)$ & $1.140(0.924,1.406)$ \\
\hline Summer & $1.058+(1.017,1.101)$ & $1.059+(1.016,1.105)$ & $1.088+(1.028,1.152)$ & $1.050(0.927,1.188)$ \\
\hline
\end{tabular}

* Adjusted for year, season, day of week, temperature, humidity, influenza, autocorrelation.

$+\mathrm{p}<0 \cdot 05$ 
Table 4 Sensitivity analysis of the association between air pollutants black smoke (BS) and sulphur dioxide $\left(\mathrm{SO}_{2}\right)$ and total mortality: coefficient and standard error from Poisson autoregressive models

\begin{tabular}{lll}
\hline & $B S$ & $S_{2}$ \\
\hline Air pollutant alone & $0.000817(0.000139)$ & $0.001140(0.000187)$ \\
+ Trend & $0.000995(0.000146)$ & $0.001574(0.000212)$ \\
+ Season & $0.000432(0.000139)$ & $0.000995(0.000212)$ \\
+ Day of week & $0.000353(0.000175)$ & $0.000933(0.000248)$ \\
+ temperature +humidity + influenza & $0.000325(0.000189)$ & $0.001036(0.000259)$ \\
+ year+ season*year & $0.000614(0.000371)$ & $0.000957(0.000382)$ \\
\hline
\end{tabular}

ticular the association with respiratory causes. These results agree with previous reports in Barcelona. ${ }^{45}$ The magnitude of the associations found for both pollutants was in the upper range of those reported. ${ }^{910}$

A second finding was the association of the oxidant pollutants $\left(\mathrm{NO}_{2}\right.$ and $\left.\mathrm{O}_{3}\right)$ with mortality, particularly in the elderly and those with cardiovascular causes. Only some reports from Los Angeles (USA) ${ }^{11}$ have previously found an association between total and cardiovascular mortality and oxidants. Los Angeles and Barcelona share similar climates, geography, sources of pollution, and levels of pollutants. On the other hand, the relation between $\mathrm{NO}_{2}$ and respiratory mortality was the lowest observed and non-significant, coinciding with non-significant associations found in previous reports on emergency department admissions for chronic obstructive pulmonary disease in Barcelona. ${ }^{4}$ Although previous studies have found a positive association between $\mathrm{NO}_{2}$ and asthma emergencies in Barcelona, ${ }^{6}$ asthma mortality has a small impact in the overall respiratory mortality, and no relation was expected between $\mathrm{NO}_{2}$ and mortality for all respiratory causes. Similarly, previous studies showed an association between $\mathrm{O}_{3}$ and hospital admissions for asthma in Vancouver, ${ }^{12}$ but the present association with respiratory mortality was observed only from the fifth lag day and it was not statistically significant.

The biological explanation for these findings seems coherent for $\mathrm{SO}_{2}$, for which a stronger association was observed for respiratory causes and in the elderly, consistent with the biological mechanisms of this pollutant. ${ }^{13}$ However, for BS the associations with cardiovascular and respiratory mortality were similar, and for $\mathrm{NO}_{2}$ and $\mathrm{O}_{3}$ the association with cardiovascular mortality was higher, but the explanations for a cardiovascular effect are unknown. A confounding effect due to $\mathrm{CO}$ should be considered, since it is a pollutant generated by motor vehicles that is firmly related to heart diseases. ${ }^{14}$ Recently, Seaton et at ${ }^{15}$ proposed a biological hypothesis for the relation between particles and cardiovascular deaths (that is, particles in susceptible subjects would increase the viscosity and coagulability of the blood, increasing the likelihood of a heart attack). This theory links with the evidence of a relationship between smoking and increases in white blood cels, ${ }^{16}$ fibrinogen and viscosity, ${ }^{17}$ which partly explained the cardiovascular risk of smoking. ${ }^{16} 17$

Why $\mathrm{SO}_{2}$ and oxidants showed a stronger relation with respiratory and cardiovascular mortality, respectively, during summer than winter is unknown. During winter people are less exposed to outdoor air than in summer which could lead to a higher misclassification in the exposure measurement. Another explanation is that competing causes of death (that is, low temperature, respiratory infections) had a much lower impact during summer. It is also possible that the toxicity of the pollution mixture varied by season and was more toxic during summer, although the concentration of volatile compounds (including some irritants) in summer is 10 times lower than in winter. ${ }^{7}$ Summer probably offers a much better scenario than winter in which to study the health effects of air pollution in places like Barcelona.

BS actually measures fine black particles from heating with coal. In Barcelona, most heating is by methane gas which does not release black particles. To what extent BS is a surrogate for respiratory particles (including non-black particles) is unknown. Misclassification due to error of measurement of the actual exposure is a common problem in studying air pollution epidemiology and probably leads to an underestimation of the true associations. ${ }^{18}$ How reliable is the specific mortality? In Barcelona, cardiovascular and respiratory deaths showed an agreement of $78 \%,{ }^{8}$ which suggests a degree of misclassification for these causes that may bias the present estimations, probably towards the null hypothesis.

The confounding effect of temperature is a keystone in the analysis of daily variations in mortality and pollution. A study in The Netherlands $^{19}$ showed the disappearance of the association due to $\mathrm{SO}_{2}$ after an appropriate adjustment for temperature. In the present analysis a great effort has been made to adjust for different forms and functions of temperature and dew point, without any changes in the pollutant coefficients. In addition, we carried out a different way of modelling temperature and humidity ${ }^{20}$ and the final inferences of the adjusted associations for $\mathrm{SO}_{2}$ and $\mathrm{BS}$ were identical to those presented here. The latter analysis ${ }^{20}$ was carried out with a different statistical methodology, using ARIMA methods to control for seasonality and extreme meteorological days, and the final inferences were the same, suggesting that present results were not spurious associations due to the statistical methods.

The search for individual pollutants related to health effects faces the quite impossible task of measuring complex exposures such as urban pollution. Conversely, the understanding of individual associations leads to biological explanations and has a direct link with the public health preventive strategy of setting standards. In the last decade, the principal pollutant of interest in air pollution epidemiology has been particles. $^{910}$ However, we have repeatedly found that $\mathrm{SO}_{2}$ has a much stronger and consistent association with the health indicator (that is, an association with respiratory mortality that is stronger than that with total mortality, opposite to the association with BS and no modification of the estimates in the sensi- 
tivity analyses, at variance with $\mathrm{BS}$ ). To what extent $\mathrm{SO}_{2}$ is a marker of fine particles ${ }^{9}$ or "toxic" by itself deserves toxicological studies and comparisons with epidemiological studies conducted in different environments.

The present positive associations coincide with most of the positive associations from reports studying the acute temporal relation between mortality and urban air pollution, and also with our previous studies on emergency department admissions. The reproducibility of positive associations between air pollutants and mortality in different places differs with the lack of clear biological explanations for how a small increase in some pollutants may cause death.

Funded by the Commission of the European Communities (CEC), Directorate General for Science, Research and Development, Environment 1991-1994 Programme.

We thank Carme Borrell and the department of Epidemiological Information from the Institut Municipal de la Salut for providing mortality data.

1 Katsouyanni K, Zmirou D, Spix C, et al. Short-term effects of air pollution on health: a European approach using epidemiologic time series data. The Aphea project: backepidemiologic time series data. The Aphea project: back-

2 World Health Organisation Air quality guidelines for Europe. Copenhagen: World Health Organisation. Regional Office for Europe, 1987. WHO Regional Publications, European series no 23

3 Aceves M, Grimalt J. Large and small particle size screening of organic compounds in urban air. Atmosphere En1993;27:251-3

4 Sunyer J, Antó JM, Murillo C, Sáez M. Air pollution and emergency room admissions for chronic obstructive pulmonary diseases. Am $\mathcal{F}$ Epidemiol 1991:134:277-86.
5 Sunyer J, Sáez M, Murillo C, Castellsagué J, Martínez J, Antó JM. Air Pollution and emergency room admissions for chronic obstructive pulmonary diseases. Am $\mathcal{F}$ Epidemiol 93;137:701-5.

6 Castellsagué J, Sunyer J, Sáez M, Antó JM. Short-term association of urban air pollution with emergency room visits for asthma. Thorax 1985;50:1051-6.

7 Aceves M, Grimalt J. Seasonality dependent particle size distributions of aliphatic and polycyclic hydrocarbons in aerosols from densely populated areas. Environmental Science Technology 19.93;23:2896-908.

8 Garcia-Benavides F, Segura Benedito A, Gadoy Laserna C. Estadisticas de mortalidad en España: pequeños problemas, grandes perspectivas. In: Alvarez-Dardet C, PortaSerra M, eds. Revisiones en salud publica. Barcelona: Doyma 1991;43-66.

9 Pope AC, Bates DV, Raizenne ME. Health effects of particulate air pollution: time for reassessment? Environ Health Perspect 1995;103:472-80.

10 Schwartz J. Air pollution and daily mortality: a review and metaanalysis. Environ Res 1994;64:36-52.

11 Kinney PL, Ozkaynak H. Associations of daily mortality and air pollution in Los Angeles county. Environ Res 1991; 54:99-120.

12 Balmes JR. The role of ozone exposure in the epidemiology of asthma. Environ Health Perspect 1993;101:219-24.

13 Carnow BW, Senior RM, Karsh R, et al. The role of air pollution in chronic obstructive pulmonary disease. $f A M A$ 1970;214:849-9.

14 Hexter AC, Goldsmith JR. Carbon monoxide: association of community air pollution with mortality. Science 1971; 172:265-66.

15 Seaton A, Macnee W, Donaldson K, Godden D. Particulate air pollution and acute health effects. Lancet 195;345: $176-8$.

16 Zalocar JB, Richard JL, Pharm Jr. Leucocyte count, smoking, and myocardial infarction. $N$ Eng $\mathcal{F}$ Med 1981;304: 465-8.

17 Yarnell JWC, Baker IA, Sweetnam PM. et al. Fibrinogen, viscosity, and white blood cell count are major risk factors for ischemic heart disease. Circulation 1991;83:836-44.

18 Hatch $M$, Thomas D. Measurement issues in environmental epidemiology. Environ Health Perspect 1993;101:49-58.

19 Mackenbach JP, Kunst AE, Looman CWN. Air pollution, lagged effects of temperature, and mortality: The Netherlands 1979-87. I Epidemiol Community Health 1993;47: $121-6$

20 Sáez M, Sunyer J, Castellsagué J, Antó JM. Relation between temperature and mortality. Int $\mathcal{F}$ Epidemiol 1995;24:57682. 